\title{
Karakteristik Dielektrik Isolator Polimer Resin Epoksi Berbahan Pengisi Abu Tongkol Jagung
}

\author{
Yuditirajab Harun ${ }^{1}$, Amelya Indah Pratiwi ${ }^{2}$ \\ Jurusan Teknik Elektro Universitas Ichsan Gorontalo \\ J1. Ahmad Najamuddin No.17 Kota Gorontalo

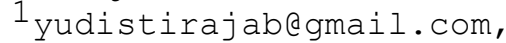 \\ 2 Amelyaindahpratiwi@gmail.com
}

Intisari - Pengembangan isolator polimer semakin meningkat dikarenakan sifat dielektrik isolator polimer lebih baik dibanding kaca dan keramik, konstruksi relatif lebih ringan, ketahanan kimia yang baik, ketahanan yang tinggi terhadap asam, memiliki sifat kedap air (hidrophobik) dan proses pembuatannya yang relatif lebih cepat dibandingkan isolator keramik dan kaca. Adapun kekurangannya yakni bahannya kurang tahan terhadap perubahan cuaca yang menyebabkan kekuatan mekanis menurun dan kerusakan fisik isolator. Kekurangan tersebut dapat diperbaiki dengan menambahkan bahan pengisi (filler) pada bahan isolator, seperti pasir silika, ataupun abu arang yang banyak mengandung silika. Penelitian ini mengkaji karakteristik dielektrik isolator polimer berbahan pengisi abu arang tongkol jagung. Bahan resin epoksi yang di gunakan adalah Dyglicidyl Ether Of Bisphenol-A (DGEBA) sebagai bahan dasar dan Metaphenylene Diamine (MPDA) sebagai bahan pengeras dengan perbandingan campuran 2:1 dan dicampurkan bahan pengisi (filler) dengan komposisi 0 gr, 15gr, 30gr. Pengujian dilakukan pada kondisi kering dan basah. Hasilnya Korona yang terjadi pada sampel dengan filler 30gr lebih lama dibandingkan dengan sampel dengan filler 15gr, dan nilai tegangan tembus yang terjadi pada sampel dengan filler $30 \mathrm{gr}$ lebih tinggi dibandingkan dengan sampel dengan filler 15gr. Dengan demikian peningkatan filler secara bertahap dapat memperbaiki nilai tegangan tembus pada sampel isolator.

Kata Kunci - Isolator Polimer, Resin Epoxy, Filler, Abu Tongkol Jagung 


\section{PENDAHULUAN}

Isolator merupakan salah satu peralatan listrik yang berfungsi untuk mengisolasi konduktor jaringan bertegangan dengan tiang penyangga pada sistem tenaga listrik. Jenis isolasi yang umum digunakan pada sistem tenaga listrik yaitu isolasi gas, isolasi cair, dan isolasi padat. Pada umumnya peralatan tegangan tinggi menggunakan isolasi padat, bahan isolasi padat yang digunakan adalah bahan dari Porselin (Keramik) dan Kaca yang memiliki kelebihan konduktivitas panas yang rendah, tahan korosi, keras dan kuat [1]. Namun bahan isolasi keramik dan gelas memiliki kelemahan dari segi mekanis yaitu berat, dan permukaannya yang bersifat menyerap air (hidrofilik) sehingga lebih mudah terjadi arus bocor (flashover) [2].

Saat ini mulai dikembangkan isolator polimer resin epoksi yang mempunyai keunggulan antara lain: sifat dielektris, konstruksi relatif lebih ringan, ketahanan kimia yang baik, ketahanan yang tinggi terhadap asam, memiliki sifat kedap air (hidrophobik) dan proses pembuatannya yang relatif lebih cepat dibandingkan isolator keramik dan kaca. Sedangkan kekurangannya antara lain: bahannya kurang tahan terhadap perubahan cuaca yang menyebabkan kekuatan mekanis menurun dan kerusakan fisik [2]. Sifat mekanis dan elektrik dari isolator tersebut dapat diperbaiki dengan menambahkan bahan pengisi (filler) seperti pasir silika dan lain-lain [3]. Untuk itu penulis mengambil judul penelitian yaitu "Karakteristik Dielektrik Isolator Polimer Berbahan Pengisi Abu Tongkol Jagung”.

\section{METODE PENELITIAN}

\section{A. Jenis penelitian}

Penelitian ini merupakan penelitian yang bersifat kuantitatif yang dilakukan pembuatan dan pengujian isolator polimer resin epoksi untuk mengetahui karakteristik dielektrik isolator polimer resin epoksi berbahan pengisi abu tongkol jagung, kemudian hasil yang diperoleh akan menjadi acuan dan perbandingan. Pengujian dielektrik pada isolator akan di lakukan di laboratorium tegangan tinggi.

\section{B. Bahan Pengujian}

Bahan dasar untuk resin epoksi yang digunakan dalam penelitian ini terdiri dari dua bagian yaitu DGEBA (Diglycidyl Ether Of Bisphenol-A) sebagai bahan dasar resin epoksi, dan MPDA (Metaphenylene diamine) sebagai pengeras/pematang, dengan type RTV (Room Temperature Vulcanization) atau mengeras dalam suhu ruang. Resin epoksi diperoleh dari Lycal Glr, adapun merek dagangnya adalah resin epoksi RTV $1011(\mathrm{~N})$. Bahan pengisi yang di gunakan yaitu abu tongkol jagung [4].

\section{Proses karbonisasi tongkol jagung}

Bahan baku tongkol jagung dikeringkan dengan proses penjemuran di bawah sinar matahari untuk menghilangkan kadar air yang terdapat pada tongkol jagung agar nantinya proses pembakaran menjadi arang dan abu lebih cepat, kemudian dimasukan kedalam tungku pembakaran dan dibakar selama 7 jam sampai menjadi abu dan tidak ada api yang tersisa atau disebut dengan proses karbonisasi, hal ini bertujuan untuk menghilangkan unsur karbon yang terdapat pada tongkol jagung sehingga yang tersisa hanya silika (SiO2) yang akan digunakan untuk memperbaiki sifat mekanis dari isolator. Lalu abu tongkol jagung tersebut diayak menggunakan saringan teh hingga halus yang hasilnya akan di campur sebagai bahan pengisi pada resin epoksi. Proses karbonisasi tongkol jagung dapat dilihat pada gambar dibawah ini:

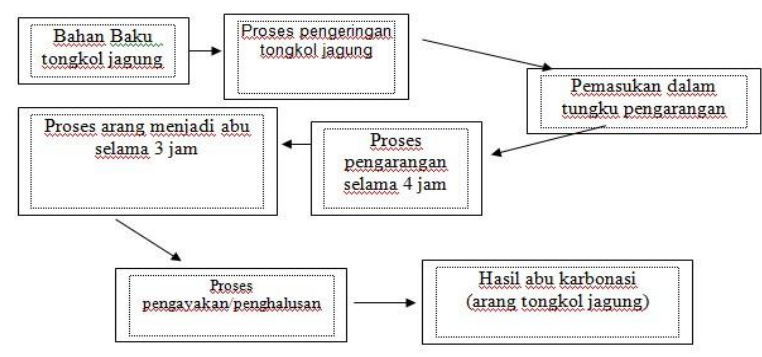

Gbr. 1 Proses karbonisasi tongkol jagung

Saat pencetakan sampel kondisi suhu dan kelembaban ruangan tidak diperhatikan karena pencampurannya dilakukan didalam ruangan sehingga suhu dan kelembaban dapat berubah dengan cepat. Kelembaban dan suhu sekitar akan mempengaruhi laju pengerasan material resin epoksi namun tidak mempengaruhi tingkat kekerasan material berdasarkan keterangan produsen 
produk resin epoksi yang digunakan. Oleh karna itu pencampuran diruangan tidak memberikan masalah, asalkan udaranya tidak berpolusi tinggi maka tidak masalah melakukannya pada ruangan demi alasan keamanan dan juga tidak mempengaruhi material yang dihasilkan. Untuk proses pencampuran bahan dan pencetakan dapat dilihat pada gambar dibawah ini:

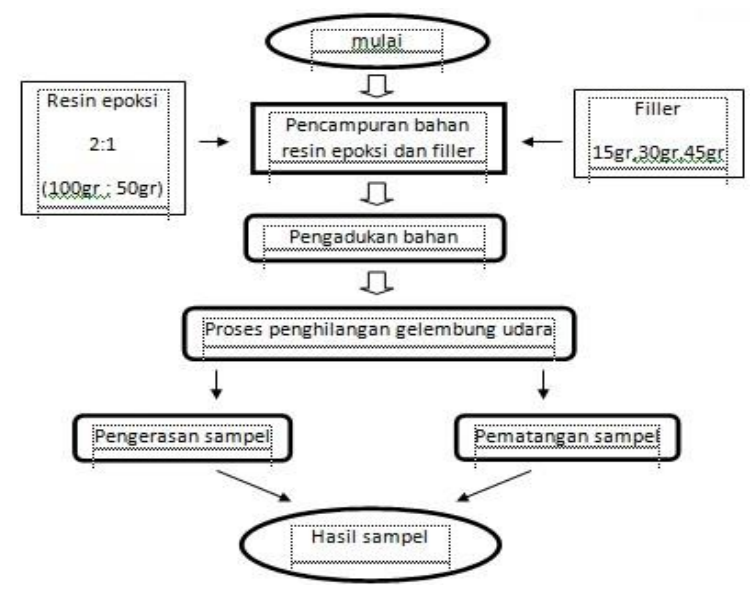

Gbr.2 Proses pencetakan dan pencampuran bahan

Komposisi bahan saat pencampuran resin epoksi yaitu antara DGEBA dan MPDA dibuat dengan komposisi yang sama pada tiap sampel uji yaitu 2:1 atau $100 \mathrm{ml}$ untuk DGEBAnya dan 50ml untuk MPDAnya yang ditakar dengan menggunakan gelas ukur dan dispo. Sedangkan untuk bahan pengisi (filler) digunakan dengan komposisi dibuat bervariasi yaitu 0gr, 15 gr, dan 30gr ditakar menggunakan timbangan digital. Sampel tanpa filler diberi nama SA00, sedangkan sampel dengan filler $15 \mathrm{gr}$ diberi nama SA01, sampel dengan filler 30gr diberi nama SA02. Berikut tabel komposisi sampel uji:

Tabel 1. Komposisi Sampel Uji

\begin{tabular}{|l|l|l|l|}
\hline SAMPEL & DGEBA & MPDA & FILLER \\
\hline SA00 & $100 \mathrm{ml}$ & $50 \mathrm{ml}$ & $0 \mathrm{gr}$ \\
\hline SA01 & $100 \mathrm{ml}$ & $50 \mathrm{ml}$ & $15 \mathrm{gr}$ \\
\hline SA02 & $100 \mathrm{ml}$ & $50 \mathrm{ml}$ & $30 \mathrm{gr}$ \\
\hline
\end{tabular}

\section{Teknik Pengujian}

Pengujian menggunakan elektroda jarum dan plat, hal ini dimaksudkan agar saat pengujian dilakukan busur listrik akan menembus bagian material (breakdown). Pada pengujiaan tegangan tembus untuk material resin epoksi yang memakai bahan pengisi abu tongkol jagung dan yang tidak memakai bahan pengisi pengujiannya di lakukan sebanyak 3 kali pengujian dengan menaikan tegangan secara perlahan sebesar $1,5 \mathrm{KV} /$ detik.

\section{E. Diagram Alir}

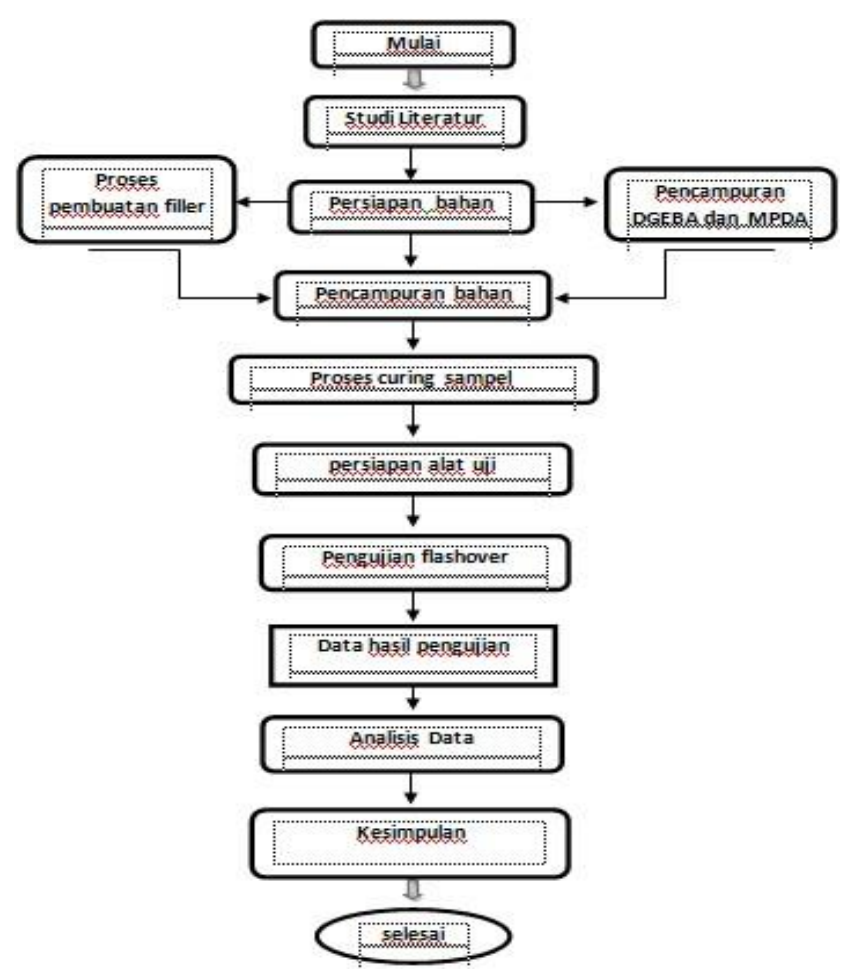

Gbr.3 Flowchart

\section{HASIL DAN PEMBAHASAN}

\section{A. Hasil pencetakan sampel}

Sampel yang sudah kering dan siap untuk diuji, diukur ketebalan dan beratnya sebagai hasil perbandingan dari penambahan filler Untuk hasil pencetakan sampel isolator dapat dilihat pada tabel 2 dibawah ini:

Tabel 2. hasil pencetakan sampel

\begin{tabular}{|c|c|c|c|}
\hline KODE & $\begin{array}{c}\text { KOMPOSISI } \\
\text { SAMPEL }\end{array}$ & TEBAL & BERAT \\
\hline SA00 & DGEBA & MPDA & $\begin{array}{c}\text { BAHAN } \\
\text { PENGISI }\end{array}$ \\
\hline SA01 & $100 \mathrm{ml}$ & $50 \mathrm{ml}$ & $0 \mathrm{gr}$ \\
\hline SA02 & $100 \mathrm{ml}$ & $50 \mathrm{ml}$ & $15 \mathrm{gr}$ \\
\hline
\end{tabular}

Hasil tabel 2 menunjukan kode sampel, presentase ketebalan dan berat dari masingmasing sampel resin epoksi, dimulai dengan sampel SA00 yang mempunyai ketebalan $30 \mathrm{~mm}$ dan berat $150 \mathrm{gr}$, kemudian sampel SA01 yang mempunyai ketebalan $35 \mathrm{~mm}$ dan 
berat $157 \mathrm{gr}$, kemudian sampel SA02 yang mempunyai ketebalan $40 \mathrm{~mm}$ dan berat $182 \mathrm{gr}$.

B. Hasil pengujian sampel resin epoksi tanpa filler (SAOO)

Hasil pengujian sampel uji resin epoksi yang tidak memakai bahan pengisi (non filler) dengan ketebalan $30 \mathrm{~mm}$ dan berat 150 gr, yang diuji sebanyak 3 kali pengujian, dengan menaikkan tegangan secara perlahan yaitu sebesar $1,5 \mathrm{KV} /$ detik sampai terjadi flashover, tegangan flashover dari sampel uji dapat dilihat pada tabel dibawah ini:

Tabel 3. Hasil pengujian sampel SA00

\begin{tabular}{|l|c|}
\hline $\begin{array}{c}\text { Sampel } \\
\text { SA00 }\end{array}$ & $\begin{array}{c}\text { Tegangan } \\
(\mathbf{k V})\end{array}$ \\
\hline Korona & $40,63 \mathrm{KV}$ \\
\hline Flashover & $74,64 \mathrm{KV}$ \\
\hline
\end{tabular}

Tabel 3 di atas adalah nilai rata-rata pengujian korona yang dilakukan sebanyak 3 kali dan hasilnya diperoleh nilai tegangan pada saat terjadi korona sebesar $40,63 \mathrm{KV}$ dan nilai tegangan rata-rata pada saat terjadi flashover sebesar 74,64KV. Grafik line perbandingan pengujian korona dan flashover pada sampel SA00 dapat dilihat dibawah ini :

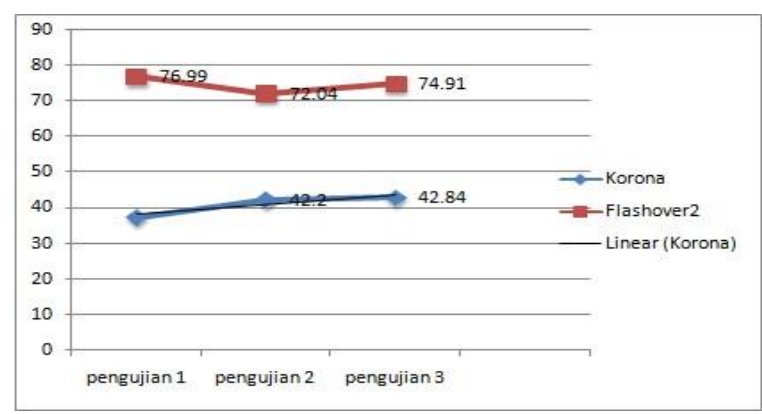

Gbr. 4 Line Pengujian Tegangan Pada Sampel Non Filler (SA001)

C. Hasil pengujian sampel resin epoksi dengan filler abu tongkol jagung $15 \mathrm{gr}$ (SA01)

Hasil pengujian sampel uji resin epoksi yang memakai bahan pengisi abu tongkol agung dengan ketebalan $35 \mathrm{~mm}$ dan berat $15 \mathrm{gr}$, yang diuji sebanyak 3 kali pengujian, dengan menaikkan tegangan secara perlahan yaitu sebesar $1,5 \mathrm{KV} /$ detik sampai terjadi flashover, dapat dilihat pada tabel dibawah ini:
Tabel 4. Hasil pengujian sampel SA01

\begin{tabular}{|l|c|}
\hline $\begin{array}{c}\text { Sampel } \\
\text { SA01 }\end{array}$ & $\begin{array}{c}\text { Tegangan } \\
\text { rata-rata } \\
(\mathbf{k V )})\end{array}$ \\
\hline Korona & 34,03 \\
\hline Flashover & 46,80 \\
\hline
\end{tabular}

Berdasarkan tabel 4 Nilai rata-rata untuk pengujian korona sebesar $34.03 \mathrm{KV}$ dan nilai rata-rata untuk pengujian flashover sebesar $46,80 \mathrm{KV}$. Untuk line perbandingan pengujian korona danflashover pada sampel SA01dapat dilihat dibawah ini:

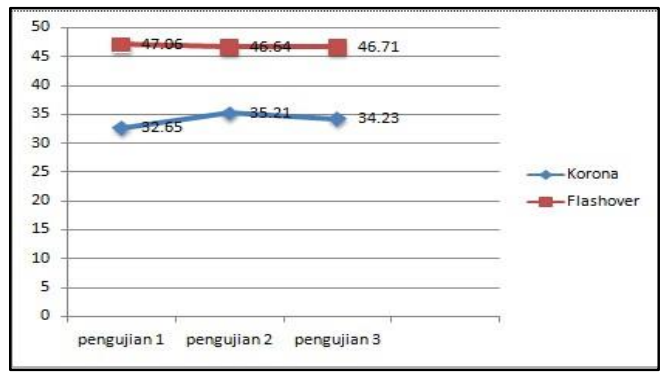

Gbr.5 Line Pengujian Tegangan Pada Sampel Dengan Filler 15ml (SA01)

D. Hasil pengujian sampel resin epoksi dengan filler abu tongkol jagung $30 \mathrm{gr}$ (SAO2)

Hasil pengujian sampel uji resin epoksi yang memakai bahan pengisi sebesar 30gr dengan ketebalan 40mm dan berat 182gr, yang diuji sebanyak 3 kali pengujian, dengan menaikkan tegangan secara perlahan yaitu sebesar ,5KV/detik sampai terjadi flashover, dapat dilihat pada tabel dibawah ini :

Tabel 5. Hasil pengujian sampel SA02

\begin{tabular}{|l|l|}
\hline $\begin{array}{l}\text { Sampel } \\
\text { SA02 }\end{array}$ & $\begin{array}{c}\text { Tegangan } \\
\text { rata-rata } \\
(\mathbf{k V})\end{array}$ \\
\hline Korona & $30,29 \mathrm{KV}$ \\
\hline Flashover & $50,67 \mathrm{KV}$ \\
\hline
\end{tabular}

Berdasarkan tabel 5 Nilai te gangan ratarata pada saat terjadi korona sebesar $30,29 \mathrm{KV}$ dan nilai tegangan flashover rata-rata sebesar $50,67 \mathrm{KV}$. Untuk line perbandingan pengujian korona dan flashover pada sampel SA02 dapat dilihat dibawah ini: 


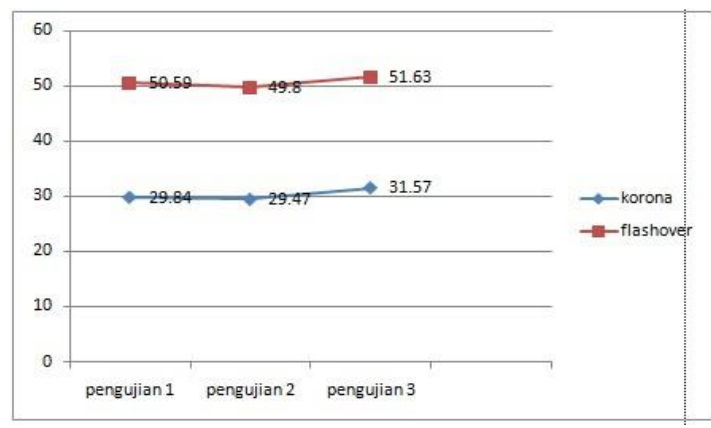

Gbr.6 Line Pengujian Tegangan Pada Sampel Dengan Filler 30ml (SA02)

\section{E. Hasil Perbandingan Dari Tiap Sampel} Yang Diuji

Berikut table perbandingan hasil pengujian sampel yang non filler dan sampel yang menggunakan filler:

Tabel 6. Perbandingan hasil pengujian tiap sampel

\begin{tabular}{|l|l|l|}
\hline KODE & $\begin{array}{l}\text { RATA- } \\
\text { RATA } \\
\text { KORON } \\
\text { A }\end{array}$ & $\begin{array}{l}\text { RATA-RATA } \\
\text { FLASHOVER }\end{array}$ \\
\hline SA00 & $40,63 \mathrm{KV}$ & $74,64 \mathrm{KV}$ \\
\hline SA01 & $34,03 \mathrm{KV}$ & $46,08 \mathrm{KV}$ \\
\hline SA02 & $30,29 \mathrm{KV}$ & $50,67 \mathrm{KV}$ \\
\hline
\end{tabular}

Pada kandungan berbahan pengisi diatas $30 \%$ bahan sulit dicetak karna campuran dari komposisi tersebut memiliki viskositas yang tinggi yang dapat membentuk gelembung udara (void) pada sampel saat pengeringan. Untuk menghilangkan gelembung udara secara maksimal harus menggunakan mesin vakum. Tetapi karna ketidakadaan mesin vakum maka proses penghilangan gelembung menjadi tidak optimal terutama pada bahan dengan komposisi filler diatas $30 \%$.

Untuk perbandingan grafik dan line dapat dilihat pada gambar dibawah ini:

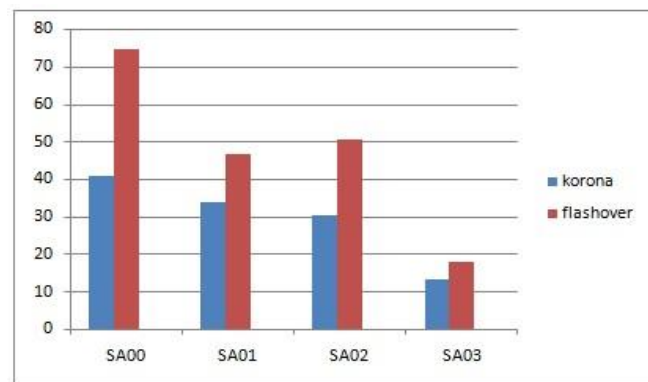

Gbr. 7 Perbandingan tegangan lashover dan korona pada semua sampel uji
F. Persentase penurunan tegangan flashover

Untuk mencari perbandingan persen atara masing- masing sampel, dapat dilihat pada rumus dibawah ini:

$\frac{V n f-V f}{V n f} \times 100 \%$

Dimana:

Vf = Tegangan tembus pada sampel

menggunakan bahan pengisi (filler).

$\mathrm{Vnf}=$ tegangan tembus pada sampel tanpa bahan pengisi non filler.

Hasil dari penurunan tegangan flashover pada tiap sampel yang menggunakan filler jika dibandingkan dengan sampel nonfiller dapat dilihat pada tabel dibawah ini:

Tabel 7. Persentase penurunan tegangan flashover

\begin{tabular}{|l|l|}
\hline \multicolumn{1}{|c|}{$\begin{array}{c}\text { PERBANDINGAN } \\
\text { SAMPEL }\end{array}$} & \multicolumn{1}{c|}{ PERSEN } \\
\hline $\begin{array}{l}\text { SA00 : SA01 } \\
(0 \mathrm{gr}: 15 \mathrm{gr})\end{array}$ & $37 \%$ \\
\hline $\begin{array}{l}\text { SA00 : SA02 } \\
(0 \mathrm{gr}: 30 \mathrm{gr})\end{array}$ & $32 \%$ \\
\hline
\end{tabular}

Dari tabel 7 dapat dilihat bahwa pengujian tiap sampel dengan komposisi berbahan pengisi abu tongkol jagung sebesar $15 \mathrm{gr}$, dan 30g yang dibandingkan dengan sampel yang tidak menggunakan berbahan pengisi mempunyai perbedaan yang signifikan jika dilihat dari kekuatan resistivitas sampel. hasil perbandingan antara sampel SA00 dengan sampel SA01 mempunyai perbedaan nilai rata-rata sebesar $37 \%$ dengan pengujian yang dilakukan sebanyak 3 kali, sedangkan perbandingan sampel SA00 dengan sampel SA02 mempunyai perbandingan nilai ratarata sebesar $32 \%$ yang diuji sebanyak 3 kali pengujian. Dengan perbandingan persen antara sampel yang menggunakan berbahan pengisi yang ditambahkan secara bertahap dengan sampel yang tidak menggunakan berbahan pengisi, didapat hasil bahwa dengan penambahan bahan pengisi 30gr mempunyai perbandingan persen yang paling kecil. 


\section{KESIMPULAN}

\section{A. Kesimpulan}

Adapun kesimpulan yang dapat diambil dari penelitian ini adalah sebagai berikut :

1. Pada komposisi filler sebesar $30 \%$ menghasilkan nilai tegangan flashover lebih tinggi dibandingkan dengan fillter $15 \%$

2. Karakteristik dielektrik isolator polimer resin epoksi dengan bahan isi abu tongkol jagung sebesar $30 \%$ lebh baik dibandingkan dengan bahan pengisi komposisi $15 \%$

3. Penambahan bahan pengii abu tongkol jagung $15 \%$ dan $30 \%$ menyebabkan penurunan tegangan flashover pada isolator polimer yang tidak menggunakan bahan pengisi.

4. Penurunan tegangan flashover pada isolator dengan penambahan bahan pengisi $15 \%$ dan $30 \%$ disebebkan karena banyaknya gelembung udara pada isolator sampel.

\section{REFERENSI}

[1] Arismunandar, A., 1987, Teknik Tegangan Tinggi, Pradnya Paramita, Jakarta.

[2] Syakur, Abdul., Hamzah Berahim, Tumiran, danrochmadi. 2011, leakage current measurement of epoxy compound with silicon rubber, Procceding ICEEI Bandung.

[3] Yuliana Prabayani, Hermawan, Abdul Syakur, 2012, jurusan teknik elekttro Universitas Diponegoro.

[4] Berahim, Hamzah, 2005, Metodologi Untuk Mengkaji Kinerja Isolasi Polimer Resin Epoksi Silane Sebagai Material Isolator Tegangan Tinggi Di Daerah Tropis.

[5] Tobing Bonggas L, Dasar teknik pengujian tegangan tinggi, penerbit PT.Gramedia, Jakarta:2003. 